\title{
Mujer joven con diarrea crónica
}

\author{
Young woman with chronic diarrhea
}

\author{
María Vares González¹, Lucía Ferreira González², Lucía Ramos Merinoํㅜ Concepción Guillén Blanco ${ }^{1}$ \\ ${ }^{1}$ Servicio de Medicina Interna. Complexo Hospitalario Universitario A Coruña. SERGAS. A Coruña. \\ ${ }^{2}$ Servicio de Medicina Interna. Hospital Arquitecto Marcide. SERGAS. Ferrol.
}

\section{Resumen}

La diarrea crónica es una entidad frecuente. Las causas son múltiples, por lo que llegar al diagnóstico definitivo puede resultar complejo acarreando con ello una demora diagnóstica que puede llegar a ser mortal. Se expone el caso de una mujer joven que desarrolla hipopotasemia severa secundaria a un VIPoma, tumor neuroendocrino secretor de péptido intestinal vasoactivo, hormona responsable del cuadro clínico: diarrea acuosa, hipopotasemia y aclorhidria.

Palabras clave. Diarrea crónica. Tumores neuroendocrinos. VIPoma. WDHA. Hipopotasemia

\section{Introducción}

Se expone el caso de una mujer joven con diarrea crónica secundaria a un vipoma. EI VIPoma es un tumor neuroendocrino pancreático (TNP) secretor de péptido intestinal vasoactivo (VIP), hormona responsable del cuadro clínico: diarrea acuosa, hipopotasemia y aclorhidria. El retraso diagnóstico medio es de 2 años. El interés del caso radica no solo en la baja incidencia de los VIPomas, sino en incluirlos en el complejo diagnóstico diferencial de la diarrea crónica, con el objetivo de adelantar el diagnóstico, tanto para evitar las graves alteraciones hidroelectrolíticas secundarias, que pueden llegar a causar la muerte, como para mejorar el pronóstico y la supervivencia a largo plazo.

\section{Caso clínico}

Mujer de 33 años sin antecedentes familiares ni personales relevantes. Consulta en el servicio de urgencias por un cuadro de 10 días de evolución consistente en debilidad muscular generalizada y progresiva, asociando calambres y sensación letárgica. En los dos meses previos había presentado vómitos y desde hacía un año describía deposiciones líquidas, de características acuosas, en número de 5-6 al día, con patrón de nocturnidad y pérdida de $15 \mathrm{~kg}$. de peso. Desde hacía 15 días estaba a tratamiento con rocecadotrilo $100 \mathrm{mg}$. y loperamida $2 \mathrm{mg}$.

\begin{abstract}
Chronic diarrhea is frequent. The causes are multiple, and reaching the definitive diagnosis can be complex. The diagnostic delay can be deadly. We describe the case of a young woman who developed severe hypokalemia secondary to VIPoma, a neuroendocrine tumor secreting vasoactive intestinal peptide, a hormone responsible for the clinical manifestations: watery diarrhea, hypokalemia and achlorhydria
\end{abstract}

Key words. Chronic diarrhea. Neuroendocrine tumors. VIPoma. WDHA. Hypokalemia

sin mejoría. Había sido estudiada en consultas externas de Medicina Interna y Digestivo realizándose endoscopias digestivas alta (EDA) y baja (EDB) y una tomografía computerizada (TC) abdominal que resultaron normales. En la exploración física destacaba: TA 100/50 mmHg, FC $111 \mathrm{lpm}$, fuerza de 3/5 en extremidades superiores y de 2/5 en extremidades inferiores (cuantificada según la escala propuesta por el Medical Research Council) con reflejos osteotendinosos abolidos en estas últimas. El examen abdominal y anorrectal era normal. Analíticamente: $\mathrm{K}^{+} 1.5 \mathrm{mEq} / \mathrm{L}, \mathrm{Ca}^{2+} 13.7 \mathrm{mEq} / \mathrm{L}$, pH 7.17, pC02 $32 \mathrm{mmHg}$ y HCO3- $18.6 \mathrm{mmol} / \mathrm{L}$. El ECG y la radiografía de tórax y abdomen no mostraron alteraciones. Se inició tratamiento sustitutivo urgente con suero salino fisiológico, cloruro potásico y sulfato de magnesio, con mejoría clínica y analítica. Durante su estancia en planta se comprobó la persistencia de la diarrea pese al ayuno. El cuadro clínico, la normalidad de los estudios descritos en la tabla 1 y el hiato aniónico en heces de -42 m0mol/Kg hicieron sospechar la existencia de un tumor neuroendocrino. Se solicitaron catecolaminas, somastotatina (SST), gastrina, glucagón, VIP y metanefrinas. Únicamente el VIP resultó elevado en dos determinaciones (119.4 pg/mL; VN menor de 30). La TC abdominal mostró una lesión de 3,2 cm. en cabeza de páncreas compatible con tumor neuroendocrino, hallazgo confirmado mediante ECO endoscopia (Figura 1) y un nódulo hipervascularizado en segmento VII hepático sugestivo de metástasis. El octreoscan no evidenció enfermedad me-

Tabla 1. Resultados de exploraciones complementarias

\begin{tabular}{|c|c|c|c|}
\hline ESTUDIOS EN SANGRE & ESTUDIOS EN HECES & ESTUDIOS ENDOS & PRUEBAS DE IMAGEN \\
\hline $\begin{array}{l}\text { - Hemograma, bioquímica básica, perfil hepático, } \\
\text { proteinograma, vitaminas: (Ø) } \\
\text { - Ferrocinética, ác. fólico: (Ø) } \\
\text { - Hormonas (TSH, PTH, CT, cortisol, catecolaminas, } \\
\text { SST, gastrina, glucagón): Ø; VIP () } \\
\text { - Autoinmunidad (ANAS, ANCAS, ASCA, IgA } \\
\text { Transglutaminasa): (-) } \\
\text { - VSG, PCR: (Ø) } \\
\text { - Serología (S. thyphi, C. jejuni y VIH): (-). }\end{array}$ & $\begin{array}{l}\text { - Coprocultivo: (Ø) } \\
\text { - Huevos y parásitos: (-) } \\
\text { - Tinción de Ziehl/Neelsen (-) } \\
\text { - Ag de C. difficile :(-) } \\
\text { - Leucocitos : (-) } \\
\text { - Grasa: (-) } \\
\text { - Sangre oculta: (-) } \\
\text { - Hiato aniónico: -42 }\end{array}$ & $\begin{array}{l}\text { - EDA: (Ø); aspirado } \\
\text { duodenal: (-) para Giardia); } \\
\text { biopsia duodenal: }(\emptyset) \\
\text { - EDB: }(\emptyset) \text {. } \\
\text { - ECOendoscopia: lesión en } \\
\text { cabeza de páncreas }\end{array}$ & $\begin{array}{l}\text { - Rx tórax/abdomen: ( } \emptyset \text { ) } \\
\text { - TGl:( } \emptyset \text { ) } \\
\text { - TC abodminal: lesión en } \\
\text { cabeza de páncreas; núdolo } \\
\text { en segmento VII hepático } \\
\text { - ECO doppler TSA: }(\emptyset) \\
\text { - Octreoscan: hipercaptación a } \\
\text { nivel de cabeza de páncreas } \\
\text { - Gammagrafía con MIBG: (Ø) }\end{array}$ \\
\hline
\end{tabular}


Figura 1. Ecoendoscopia: lesión en cabeza de páncreas compatible con tumor neuroendocrino

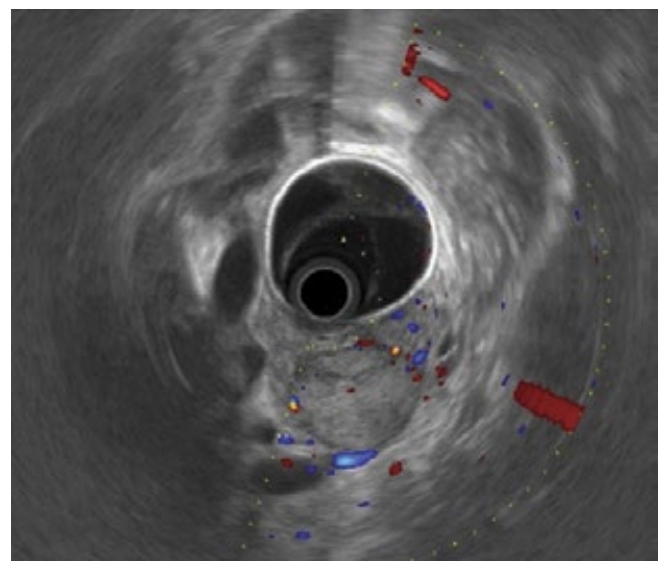

Figura 2. Imagen macroscópica del nódulo extirpado cuya histología confirmó vipoma

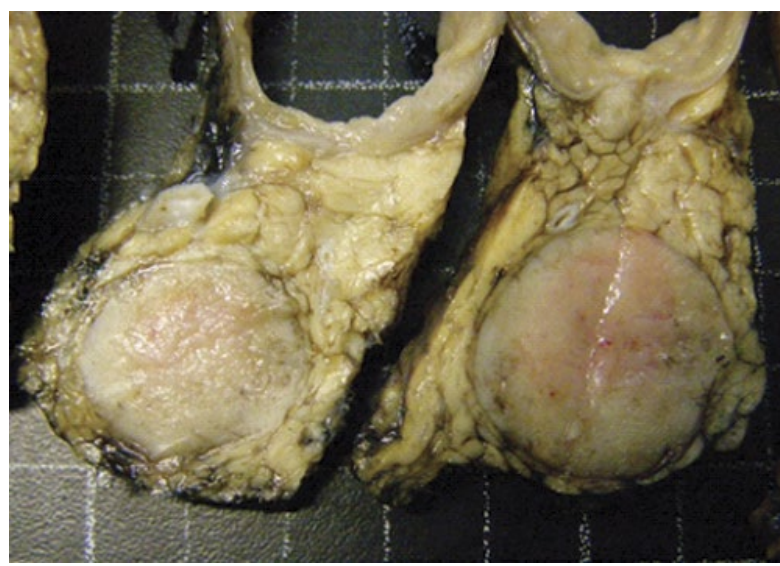

tástasica. Se inició tratamiento con octreótide subcutáneo y se realizó tratamiento quirúrgico mediante duodenopancreatectomía cefálica con preservación pilórica, colecistectomía y exéresis del nódulo hepático (Figura 2). El análisis histológico confirmó la existencia de un tumor de islotes pancreáticos (positivo para cromogranina, aisladas células a gastrina y calcitonina) con criterios histológicos de benignidad, sin invasión de los ganglios linfáticos y que el nódulo hepático correspondía con una hiperplasia nodular. Cinco años después de la intervención, la paciente permanece asintomática, sin necesidad de tratamiento farmacológico y sin evidencia radiológica de recidiva de la enfermedad.

\section{Discusión}

La diarrea puede definirse de forma pragmática como la emisión de heces de escasa consistencia o líquidas más de tres veces al día y/o un volumen de heces mayor de $200 \mathrm{~g}$. La cronicidad queda determinada por una duración mayor de 4 semanas $^{1}$. Su prevalencia en el mundo occidental es del 4-5\%2. Establecer un algoritmo diagnóstico de carácter práctico resulta complejo.
La historia clínica es fundamental. En primer lugar, debemos diferenciar entre diarrea orgánica o funcional. Orientan a organicidad la duración menor de tres meses, el patrón continuo y de nocturnidad así como la pérdida de peso. Factores de riesgo que aumentan la probabilidad de un origen orgánico y que deben incluirse en la anamnesis dirigida serían: una historia familiar relevante, cirugías, radioterapia o enfermedad pancreática previa, enfermedades sistémicas (hipertiroidismo, DM, enfermedades inflamatorias, SIDA, déficit lg...), toma de alcohol, fármacos o sustancias osmóticamente activas (sorbitol)... Por el contrario, la presencia de los criterios ROMA $\|^{3}$ y la edad menor de 45 años son sugestivos de patología funcional. En la exploración física, muchas veces normal, debe descartarse incompetencia del esfínter anal o la presencia de fisuras. Aunque muy infrecuentes, ciertos hallazgos (hiperpigmentación, eritema migratorio necrotizante...) apuntan a la causa de la diarrea. El estudio analítico inicial debe incluir: hemograma,

Tabla 2. Causas de diarrea crónica según el mecanismo fisiopatológico

\begin{tabular}{|c|c|c|c|c|}
\hline OSMÓTICA & ESTEATORREA & SECRETORA & INFLAMATORIA & MOTORA \\
\hline $\begin{array}{l}\text { - Laxantes osmóticos } \\
\text { (lactulosa...) } \\
\text { - Déficit de lactasa } \\
\text { - HC no absorbibles } \\
\text { (sorbitol...) }\end{array}$ & $\begin{array}{l}\text { - Malabsorción: } \\
\text { enfermedades mucosas } \\
\text { (celiaquía, Whipple, } \\
\text { abetalipoproteinemia); } \\
\text { isquemia mesentérica; } \\
\text { sobrecrecimiento } \\
\text { bacteriano; síndrome } \\
\text { del intestino corto; } \\
\text { obstrucción linfática } \\
\text { - Maldigestión: insuficiencia } \\
\text { pancreática exocrina, } \\
\text { concentración luminal } \\
\text { elevada de AB, cirugía } \\
\text { bariátrica y hepatopatía. }\end{array}$ & $\begin{array}{l}\text { - Malabsorción AB } \\
\text { - Toxinas bacterianas (V. } \\
\text { cholerae, S. aureus) } \\
\text { - Protozoos (G.lambia, } \\
\text { Cryptosporidium) } \\
\text { - Fármacos (colchicina, } \\
\text { teofilina) y tóxicos } \\
\text { - TNE: gastrinoma, VIPoma, } \\
\text { SSToma, Carcinoide, } \\
\text { carcinoma medular de } \\
\text { tiroides, mastocitosis } \\
\text { - Enfermedad de Addison } \\
\text { - Colistis microscópica } \\
\text { - Cáncer de colon, linfoma } \\
\text { - Diverticulitis, vasculitis, Ell } \\
\text { - Ablación o fístula intestinal }\end{array}$ & \begin{tabular}{|l} 
- Ell \\
- Diverticulitis \\
- Infecciones: \\
TBC, C.difficile, \\
enterobacterias, CMV, \\
HS, estrongiloidiasis, \\
amebiasis.. \\
- Colitis isquémicas \\
- Colitis rádica \\
- Cáncer de colon, linfoma \\
- Trastornos inmunitarios de \\
la mucosa (GE eosinofilica, \\
alergia a alimentos, EICH, \\
inumonodeficiencias, \\
enfermedad de Behcet)
\end{tabular} & $\begin{array}{l}\text { - Hipermotilidad: SII, } \\
\text { hipertiroidismo, } \\
\text { síndrome postvagotomía, } \\
\text { postsimpatectomía, } \\
\text { neruopatía diabética, } \\
\text { fármacos, malabsorción } \\
\text { AB, HDA, reseción íleo- } \\
\text { cólica, ISR } \\
\text { - Hipomotilidad } \\
\text { sobrecrecimiento } \\
\text { bacteriano: eslerodermia, } \\
\text { DM, pseudobstrución, } \\
\text { amiloidosis, hipotiroidismo } \\
\text { - EP } \\
\text { - Impactación fecal } \\
\text { - Diverticulosis }\end{array}$ \\
\hline
\end{tabular}

AB: ácidos biliares; TNE: tumores neuroendocrinos; Ell: enfermedad inflamatoria intestinal; CMV: citomegalovirus; HS: herpes simple; GE: gastroenteritis; EICH: enfermedad de injerto contra huésped; SIl: síndrome del intestino irritable; HDA: hemorragia digestiva alta; ISR: insuficiencia suprarrenal; DM: diabetes mellitus; EP: enfermedad de Parkinson. 
urea, electrolitos, perfil hepático, vitamina B12, ácido fólico, ferrocinética, VSG, PCR y TSH. Ha de considerarse también en esta primera fase la realización de test serológicos para enfermedad celíaca, al tratarse de la enteropatía más frecuente en el mundo occidental ${ }^{4}$. Especialmente si existe historia de viajes a zonas de alto riesgo debe realizarse coprocultivo y estudio de huevos y parásitos en heces (sensibilidad del 60-90\%). La diarrea facticia, también debe ser descartada. El volumen de heces suele ser menor de $200 \mathrm{~g}$./día. Si se añade agua 0 sustancias hipotónicas a las heces su osmolaridad será menor de $290 \mathrm{mosmol} / \mathrm{Kg}$. La presencia de laxantes debe detectarse mediante espectometría o cromatografía; los test de alcalinización han quedado obsoletos ${ }^{4}$. En este momento puede existir un diagnóstico de probabilidad que nos permita realizar estudios dirigidos o tratamiento empírico. En caso contrario, debemos pasar a una segunda fase. Los estudios en heces ${ }^{5}$ pueden servir como base para clasificar la diarrea según su mecanismo fisiopatológico (acuosa -osmótica o secretora-, inflamatoria, esteatorreica o motora (Tabla 2), orientando la actitud diagnóstica (Tabla 3) y evitando estudios innecesarios ${ }^{6}$, si bien ninguno de los test fecales ha demostrado una rentabilidad que obligue a realizarlos 4 . La malabsorción de carbohidratos produce diarreas osmóticas, caracterizadas por un hiato osmolar en heces mayor de $125 \mathrm{mosmol} / \mathrm{Kg}$ y por ceder con el ayuno. El hiato aniónico es menor de $50 \mathrm{mosmo} / \mathrm{Kg}$ en la diarrea secretora y generalmente está asociada a grandes pérdidas de volumen ${ }^{6}$. Es aquí donde se encuadran los trastornos neuroendocrinos. Por su escasísima frecuencia, solo tras haber descartado otras causas deben solicitarse estudios hormonales (VIP, gastrina, glucagón, catecolaminas, 5-HIAA en orina) $)^{4}$. En la diarrea inflamatoria la colonoscopia e ileoscopia con biopsias es el patrón oro, ya que conduce al diagnóstico en el 15-20\% de los casos y hasta en el $40 \%$ si existe sospecha de Ell. En pacientes menores de 45 años, pudiese ser suficiente con realizar sigmoidoscopia flexible, por presentar similar rentabilidad diagnóstica ${ }^{4}$. El papel de la sangre oculta en heces no está definido en la diarrea crónica. Para confirmar la presencia de esteatorrea, la clásica cuantificación de la grasa fecal en heces durante tres días y los test del aliento deben abandonarse ${ }^{4}$. Una alternativa aceptable es la determinación de la concentración de grasa en heces (g. grasa fecal/ $100 \mathrm{~g}$ de heces húmedas), siendo muy sugestivos de esteatorrea cifras mayores de $13 \mathrm{~g}$. grasa/100 $\mathrm{g}$ de heces. Si existe alta sospecha de malabsorción a nivel del intestino delgado, y aunque la serología sea negativa para enfermedad celíaca, debe realizarse endoscopia con biopsia de duodeno distal. Esta estrategia ha suplantado muchos de los antiguos test. El tránsito gastrointestinal con bario 0 la enteroclisis deben reservarse para aquellos casos en los que la histología duodenal es normal. De los test no invasivos que determinan la insuficiencia del páncreas exocrino, la elastasa fecal es el más sencillo, manteniendo la misma especificad y sensibilidad que el resto ${ }^{4}$. La CPRE es la mejor técnica para valorar las anormalidades ductales, si bien es probable que se vea suplantada por la colangioRM, menos invasiva. Para valorar el sobrecrecimiento bacteriano el cultivo del aspirado duodeno-yeyunal o de biopsias no lavadas de intestino delgado continua siendo la elección, pero falta estandarización y un resultado positivo no refleja significado clínico. El test se-HACT es sensible midiendo la malabsorción de ácidos biliares, pero su disponibilidad es reducida. Dadas las limitaciones de los métodos actuales para valorar la insuficiencia pancreática, el sobrecrecimiento bacteriano y la malabsorción de ácidos biliares, con mucha frecuencia se realiza ensayo terapéutico (enzimas pancreáticos, antibióticos y colestiramina, respecti-

Tabla 3. Orientación diagnóstica ante una diarrea crónica

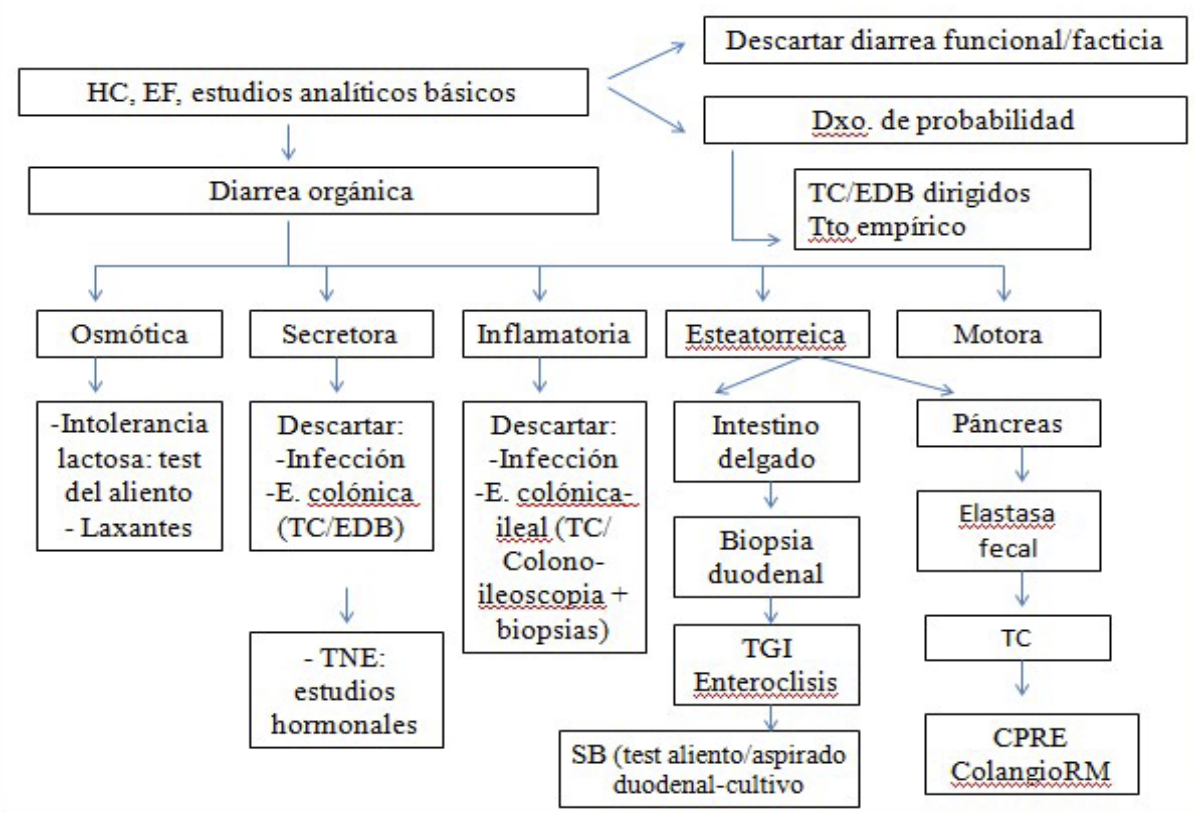

HC: historia clínica. EF: exploración física. TC: tomografía computerizada. EDB: endoscopia digestiva baja. TNE: tumores neuroendocrinos. TGl: tránsito gastrointestinal. SB: sobrecrecimiento bacteriano. CPRE: colangiopancreatografía retrógrada endoscópica. RM: resonancia magnética. 
vamente); el valor diagnóstico del mismo no ha sido evaluado. Sin embargo, y pese a los exhaustivos protocolos, parece que un tercio de los pacientes quedará sin diagnóstico. Corresponde a diarreas acuosas, "idiopáticas" autolimitadas o facticias no diagnosticadas ${ }^{7}$. Dado que en la mayoría de los casos el pronóstico global es bueno, realizar más investigaciones no resulta rentable y debe iniciarse tratamiento sintomático.

EI VIPoma, también denominado síndrome de Vermer-Morrison" "syndrome of WDHA" (watery diarrhea, hypokalemia, and achlorhydria) o cólera pancreático es un tumor neuroendocrino secretor de VIP. La incidencia es de 1 de cada 10 millones de personas al año $0^{9}$. El 80\% de los VIPomas se localizan en el páncreas (principalmente en la cola y suelen ser lesiones únicas mayores de $3 \mathrm{~cm}$.), si bien se ha descrito secreción de VIP en carcinomas broncogénicos, carcinomas de colon, feocromocitomas... En un 5\% de los pacientes forman parte de una neoplasia endocrina múltiple tipo 1 (MEN1) ${ }^{10}$. Predominan ligeramente en el sexo femenino con una distribución bimodal (2-4 años; 30-50 años). En el momento del diagnóstico existe enfermedad metastásica en el 60-80\% de los casos. El diagnóstico de VIPoma requiere la presencia de diarrea secretora, niveles elevados de VIP (>75 pg/mL) y la identificación del tumor pancreático. El cuadro clínico y las alteraciones hidroelectrolíticas son consecuencia de la producción excesiva y no controlada de VIP, cuyo principal efecto es la inducción de la secreción intestinal de cloro y bicarbonato, con disminución de la absorción de sodio. Se le atribuyen otras acciones, como vasodilatación periférica, inhibición de la secreción ácida gástrica, glucogenólisis, relajación de la fibra muscular lisa intestinal y osteolisis. El síntoma clínico más característico es la diarrea acuosa con un volumen siempre mayor de $700 \mathrm{~mL}$ día y de hasta 3 L/día en el $70 \%$ de los casos, lo que puede provocar shocks hipovolémicos ${ }^{11}$. El dolor abdominal es leve o está ausente. Otros síntomas asociados incluyen pérdida de peso (72\%), flushing (20\%), vómitos, calambres, letargia... La atonía vesicular justifica la posibilidad de colelitiasis. Analíticamente existe hipopotasemia (90-100\%), acidosis metabólica hiperclorémica, hipoclorhidria (75\%), hiperglucemia (25-50\%) e hipercalcemia (25-76\%; debida en la mayoría de los casos a hiperalbuminemia). La RM es superior a la TC por su mejor definición de los tejidos blandos, pero la mayor disponibilidad y la sensibilidad cercana al 100\% para tumores mayores de $3 \mathrm{~cm}$. hacen del TC la técnica diagnóstica habitual. Si el TNE se localiza en la cabeza del páncreas la ECO-endoscopia es la técnica de elección. El octreoscan es el pilar para la detección de receptores de SST identificando enfermedad metastásica, pero el PET utilizando análogos de la SST marcados con Ga-68 es superior y debe ser utilizado si está disponible. El PET con marcadores especializados (18FDOPA and 11C-5-hydroxytryptophan) ofrece unos resultados superiores a los del octreoscan; limitado a centros especializados, son utilizados como herramienta en casos de manejo complejo. La posibilidad de fusionar los estudios funcionales y morfológicos mediante el PET/TC permite que la precisión diagnóstica sea cada vez mayor $^{12,13}$. El tratamiento agudo consiste en la corrección de las alteraciones hidroelectrolíticas y el aporte de volumen lo que resultan de vital importancia ya que la principal causa de la muerte es el fracaso renal agudo asociado a la hipopotasemia. La resección quirúrgica completa supone por el momento el único tratamiento curativo. En los casos en los que no se consigue localizar el tumor algunos autores proponen la pancreatectomía distal "ciega". En los pacientes con tumores irresecables no se ha demostrado la eficacia de la citorreducción quirúrgica. El tratamiento de elección son los análogos de la SST que permiten el control sintomático de la diarrea en más del $80 \%$, sin existir evidencia de su eficacia antitumoral ${ }^{14}$. En los casos refractarios la asociación de corticoides o el interferón alfa pueden ser de utilidad. El tratamiento de la enfermedad metastásica hepática puede realizarse mediante resección quirúrgica en caso de afectación unilobar, embolización arterial o ablación. En casos aislados se ha realizado trasplante hepático. La experiencia con la quimioterapia sistémica es limitada. Los anti- $\mathrm{H}_{2} 0$ los IBP están indicados en el posoperatorio inmediato. El seguimiento postresección debe realizarse a los 3 y a los 6 meses, con marcadores tumorales (VIP, cromogranina) y prueba de imagen (TC/RM). Posteriormente, será suficiente con revisiones anuales y determinación del VIP. La mediana de supervivencia es de 103 meses. Soga and Yakuwa ${ }^{15}$ observaron una supervivencia a los 5 años del 94,4\% en ausencia de metástasis y del 59.6\% con enfermedad metastásica.

\section{Bibliografía}

1. Fine $K D$, Schiller $L R$. AGA technical review on the evaluation and management of chronic diarrhea. Gastroenterology. 1999; 116:1464-86.

2. Schiller LR. Diarrhea. Med Clin North Am. 2000; 84:1259-74.

3. Talley NJ, Stanghellini V, Heading RC, Koch KL, Malagelada JR, Tygat GNJ. Functional gastroduodenal disorders. Gut. 1999; 45:37-42.

4. PD Thomas, A Forbes, J Green, P Howdle, R Long, R Playford, M Sheridan et al. Guidelines for the investigation of chronic diarrhoea, 2nd edition. Gut 2003; 52(Suppl V):v1-v15.

5. Steffer KJ, Santa Ana CA, Cole JA, Fordtran JS. The practical value of comprehensive stool analysis in detecting the cause of idiopathic chronic diarrhea. Gastroenterol Clin North Am. 2012 Sep; 41(3):539-60.

6. Schiller LR. Definitions, pathophysiology and evaluation of chronic diarrhea. Best Pract Res Clin Gastroenterol. 2012 0ct; 26(5):551-62.

7. Afzalpurkar RG, Schiller LR, Little KH, Santangelo WC, Fordtran JS. The self-limited nature of chronic idiopathic diarrhea. N Engl J Med 1992; 327:1849-52.

8. Verner JV, Morrison AB. Islet cell tumor and diarrhea. A syndrome of refractory watery diarrhea and hypokalemia. Am J Med. Sep 1958; 25(3):374-80.

9. Friesen SR. Update on the diagnosis and treatment of rare neuroendocrine tumors. Surg Clin North Am. 1987; 67(2):379.

10. LecorguilléM, Hammel P, Couvelard A, O'Toole D, Ratouis A, Belghiti J, Lévy P, Ruszniewski P. Jejunal vipoma. Gastroenterol Clin Biol. 2004; 28(8-9):797.

11. Grier JF. WDHA (watery diarrhea, hypokalemia, achlorhydria) syndrome: clinical features, diagnosis, and treatment. South Med J. 1995; 88(1):22.

12. Nikou GC, Toubanakis C, Nikolaou P, Giannatou E, Safioleas M, Mallas E, Polyzos A. VIPomas: an update in diagnosis and management in a series of 11 patients. Hepatogastroenterology. 2005; 52(64):1259.

13. Sundin $A$. Radiological and nuclear medicine imaging of gastroenteropancreatic neuroendocrine tumours. Best Pract Res Clin Gastroenterol. 2012 Dec; 26 (6):803-18.

14. Eriksson B, Oberg K. An update of the medical treatment of malignant endocrine pancreatic tumors. Acta Oncol. 1993; 32(2):203.

15. Soga J, Yakuwa Y. Vipoma/diarrheogenic syndrome: a statistical evaluation of 241 reported cases. J Exp Clin Cancer Res. Dec 1998; 17(4):389-400. 